\title{
MODELO DE GESTÃO DA MUDANÇA E APRENDIZADO ORGANIZACIONAL
}

\section{MODEL OF CHANGE MANAGEMENT AND LEARNING ORGANIZATION}

\author{
Marcelo Augusto Oliveira da Justa ${ }^{1}$; Nilson Rodrigues Barreiros ${ }^{2}$ \\ ${ }^{1}$ Universidade Federal do Amazonas - UFAM - Manaus - Brasil \\ marcelo.justa@bol.com.br \\ ${ }^{2}$ Universidade Federal do Amazonas - UFAM - Manaus - Brasil \\ nilbarr@ufam.edu.br
}

\begin{abstract}
Resumo
O ambiente altamente competitivo em que as organizações estão inseridas é um fator determinante para que as empresas adotem uma postura de mudanças constantes, caso contrário, correm o risco de serem descartadas por um mercado cada vez mais criterioso na escolha de seus parceiros. No entanto, conduzir adequadamente as transformações não é uma tarefa simples, pois requer uma gestão adequada do processo de transição, o qual deve ser construido e sedimentado passo a passo, envolvendo mudanças de hábitos, pensamentos, sentimentos e percepções que antes estavam inseridos na mentalidade das pessoas, fazendo parte da identidade da empresa. Neste contexto, o presente artigo apresenta um modelo de gestão que faz uso de técnicas e ferramentas que promovem o gerenciamento do estado atual para o estado futuro e ainda desenvolve uma mentalidade de aprendizado contínuo. As conclusões desse trabalho revelam que o modelo contribuiu para a superação dos velhos paradigmas, fomentando o ajuste necessário para uma cultura organizacional de alto desempenho, favorecendo a formação do espírito de equipe, a melhoria do desempenho operacional e do ambiente de trabalho.
\end{abstract}

Palavras-chave: Gestão da Mudança, Aprendizado Organizacional, 5s, MPT, Kaizen.

\section{Introdução}

Segundo Porter (1999) as empresas buscam continuamente melhorar seus processos com custos cada vez menores porque essa atitude é forçada pelas exigências dos clientes e pela competitividade global, pois para competir com eficácia neste ambiente altamente competitivo, as empresas devem procurar inovar e aprimorar suas vantagens competitivas.

$\mathrm{O}$ autor ainda reforça que as organizações devem acompanhar as contínuas mudanças impostas por um mercado cada vez mais criterioso na escolha de seus parceiros. Essas transformações afetam todas as companhias, de pequeno, médio e grande porte, não importando o segmento em que atuam.

Para Senge (2004) uma das maneiras de acompanhar esta nova realidade é o aperfeiçoamento permanente da empresa, envolvendo todos os funcionários, conscientizando-os de 
que somente pelo esforço conjunto de cada um é que a empresa sobreviverá e poderá crescer e manter os progressos conquistados. É neste cenário que surgem as organizações que aprendem, diante de uma necessidade emergente das empresas para melhorarem seus processos, reduzindo custos e inovando constantemente para que possam se adaptar às mudanças sociais e tecnológicas, bem como aos contínuos desafios impostos pela economia num ambiente altamente competitivo.

Portanto, a falta de um método eficaz para a gestão do processo de renovação organizacional foi a motivação para o desenvolvimento do modelo aqui apresentado, o qual promove a mudança organizacional contínua por meio do uso integrado das ferramentas de 5s - Housekeeping e MPT Manutenção Produtiva Total, combinadas aos eventos de kaizen.

A combinação dos eventos de kaizen com o uso integrado dessas duas ferramentas, estabelece uma inovação metodológica para a gestão da mudança, pois maximiza os pontos de melhorias das ferramentas de $5 \mathrm{~s}$ e MPT, tornando-as mais poderosas no sentido de reduzir as perdas no processo produtivo e maximizando o retorno desejado por meio das melhorias realizadas nos equipamentos, produtos e processos.

Segundo Tavares (2007) a maioria das organizações gasta entre 10\% e 12\% do orçamento geral na manutenção de seus equipamentos. Quando as empresas utilizam métodos pró-ativos e, com um programa apropriado de manutenção, os serviços planejados com um programa regular se reduzem em 25\%. Portanto, ao longo da vida de um equipamento, os custos de operação e manutenção são superiores seis vezes ao custo original do próprio equipamento.

Segundo Silva (2001) as maiores dificuldades encontradas na implantação de novas filosofias é a mudança da cultura em todos os níveis hierárquicos, ponto fundamental para a busca da excelência dos seus processos.

Uma pesquisa realizada por uma empresa global de consultoria (Bain \& Company, 2003), constatou que metade dos 223 executivos que participaram do levantamento de dados afirmaram que as suas empresas não possuem sistemas e habilidades suficientes para realizar uma gestão efetiva da mudança. Eles ainda concluem que 70\% dos programas de mudança falham.

Ocorre que a realidade da mudança é de uma transição complexa, o qual deve ser construída e sedimentada passo a passo, pois envolve mudanças de hábitos, pensamentos, sentimentos e percepções que antes estavam inseridos no dia-a-dia das pessoas e que fazem parte da identidade da empresa. Devido a esses entraves, a aplicação das ferramentas do $5 \mathrm{~s}$ e MPT também tem se mostrado complexa, requerendo um gerenciamento adequado para que as barreiras da resistência humana sejam quebradas.

Entretanto, esse ajuste na cultura organizacional começa a partir da criação de um ambiente favorável para que a transformação ocorra, pois mesmo a mais elaborada estratégia de negócio e o mais moderno aparato tecnológico não conseguem alavancar resultados positivos sem que haja o 
engajamento dos seus colaboradores. Portanto, o artigo tem como objetivo geral apresentar um modelo que tem como finalidade o gerenciamento bem-sucedido do processo de mudança.

\section{Metodologia}

$\mathrm{O}$ artigo relata um estudo de caso realizado em uma organização transacional, com filial instalada no PIM (Pólo Industrial de Manaus). Os trabalhos realizados, bem como os resultados alcançados, contaram com uma abordagem do tipo pesquisa-ação.

Segundo Andaloussi (2004) a pesquisa ação tem a função de diagnosticar uma situação, iniciar uma ação, acompanhá-la, observá-la, conferir-lhe sentido, avaliando-a e incitando-a a desencadear novas ações. A pesquisa permite analisar uma situação para trazer auxílio, esclarecer o significado do comportamento dos diferentes parceiros e também reduzir as divergências entre participantes para alcançarem objetivos comuns.

$\mathrm{O}$ autor destaca a relação entre pesquisador e partes interessadas, contribuindo para a produção de novos saberes. Neste contexto, o envolvimento das pessoas permite mobilizar uma energia humana construtiva que reduz drasticamente os custos da pesquisa. $\mathrm{O}$ engajamento dos interessados permite desenvolver mão-de-obra qualificada para analisar e resolver problemas, além de possibilitar a conjugação dos interesses do pesquisador e dos atores implicados, pelo qual irá criar uma cooperação para o alcance de objetivos comuns.

O mesmo ainda destaca o compromisso com a mudança. A mudança é o objetivo da pesquisa-ação, pelo qual prática e saber são, ao mesmo tempo, fonte e produto da mudança. Nessa ótica, mudança não é sinônimo de aplicação de uma teoria, é o produto das transformações simultâneas da ação e da reflexão continuamente renovadas. O cruzamento dos pontos de vista de todos os participantes possibilita o permanente ajuste dos meios para que alcancem novos cenários. Nesse contexto, destaca-se o papel do pesquisador que não se contenta em apenas produzir conhecimento, isto é, passa a interagir com os atores para também produzir o resultado esperado.

\section{Manutenção Produtiva Total - MPT}

De acordo com o Instituto Japonês de Engenharia de Fábrica (Japanese Institute of Plant Engineers - JIPE), define-se MPT como um termo base de uma estratégia de manutenção projetada para maximizar a eficiência dos equipamentos por estabelecer um compreensivo sistema de manutenção da produção cobrindo toda a vida útil dos equipamentos, controlando todos os campos relacionados aos equipamentos e o que está envolvendo cada um deles.

Descreve-se, portanto, todo o relacionamento da sinergia entre as funções organizacionais e assim promovendo a manutenção produtiva por meio de um gerenciamento motivacional e voluntário em pequenos grupos de atividades (SHARMA et al., 2006). 
Os autores destacam que todas essas atividades de aperfeiçoamento dos equipamentos são chamadas de Manutenção Produtiva. A evolução desta manutenção aconteceu através da colocação de operadores e mantenedores em trabalhos de equipe, com o objetivo de resolverem os problemas dos equipamentos. Foi criado então o primeiro e mais importante pilar, a Manutenção Autônoma, onde os operadores assumem várias responsabilidades sobre a sua máquina de atuação. A partir deste momento passa a se chamar Manutenção Produtiva Total.

Palmeira e Tenório (2002) confirmam que a MPT promove mudanças organizacionais por meio do desenvolvimento e capacitação das pessoas para ações de prevenção e de melhoria contínua em relação aos equipamentos, garantindo o aumento da confiabilidade dos mesmos e da capabilidade dos processos. Nesse sentido os técnicos de manutenção e os operadores de produção ganham importância fundamental quanto ao aprimoramento de seus resultados por meio do trabalho conjunto das duas áreas.

Para o autores, a MPT entra nos detalhes das perdas na produção relacionadas a máquina realizando um trabalho sistemático de redução dessas perdas, proporcionando uma mudança na organização e com resultados bastante significativos. A mudança desejada acontece de forma natural quando na aplicação da metodologia dos pilares de manutenção autônoma, manutenção planejada e nos grupos de melhorias.

\section{5s - Housekeeping}

Segundo Paladini (2000) o 5s foi concebido por Kaoru Ishikawa, no Japão na década de 1950 e foi aplicado com a finalidade de reorganizar o país após a Segunda Guerra Mundial, quando vivia a chamada crise da competitividade. Até hoje, é considerado o principal instrumento de gestão da qualidade e da produtividade utilizado no Japão devido a sua eficácia. O mesmo também pode ser considerado como um sistema organizador, mobilizador e transformador de pessoas e organizações. A ferramenta é bastante básica e deve preceder qualquer iniciativa de mudança em uma empresa.

O autor reforça que a técnica alcança resultados práticos, pois visa estabelecer e manter a qualidade do ambiente de trabalho numa organização para assegurar o atendimento aos padrões e promover o espírito da melhoria contínua. O resultado é uma empresa, no qual as pessoas dedicam maior ênfase à qualidade de vida no ambiente de trabalho, já que trabalhar com segurança, ter um rendimento elevado, trabalhar em um ambiente descontraído, limpo, organizado, climatizado, com pessoas positivas e incentivadoras, é fundamental para o aumento da produtividade de qualquer tipo de processo.

$\mathrm{O}$ autor ressalta que os $5 \mathrm{~s}$ também podem ser implantados como uma ferramenta de transformação que, ao longo do tempo, passa a ser incorporado na rotina das pessoas, contribuindo 
para a conquista da qualidade total e tendo como vantagem o fato de provocar mudanças comportamentais em todos os níveis hierárquicos, além de proporcionar a eliminação dos desperdícios, a redução dos custos e a promoção de uma vantagem competitiva frente à concorrência.

\section{Kaizen}

Segundo Ohno (1997), o termo japonês para a melhoria contínua é o kaizen que faz uso do trabalho em equipes para a solução de problemas, documentando e melhorando processos, coletando e analisando dados. Por meio do kaizen, autoriza-se as pessoas a agir na correção de problemas e lhes ensinamos como fazê-lo corretamente.

O autor ressalta que as pessoas aprendem a buscar as causas, ao invés dos "culpados", conseguindo-se com isto soluções efetivas e, de quebra, um ambiente de maior entendimento e melhores relacionamentos entre a equipe. Com o kaizen, abate-se a cultura de "varrer a sujeira para debaixo do tapete", a cultura da tolerância com as falhas e perdas de todo tipo. Ocorre também uma mobilização em toda a equipe para o combate aos erros e aos desperdícios, em todos os aspectos e por toda a organização.

Para Ohno (1997) o que se revela ao implantar o kaizen, como de resto ao se implantar qualquer programa de gerenciamento participativo é que, na realidade, todas as pessoas gostam, apreciam e têm grande orgulho em fazer corretamente o seu trabalho, e se decepcionam quando este não apresenta os resultados esperados. Portanto, só deixam de desempenhar corretamente o serviço quando uma das três condições acima ocorre.

$\mathrm{O}$ autor reforça que o kaizen acaba revelando como as pessoas apreciam e buscam a satisfação do trabalho bem feito. Na verdade, torna-se mais fácil mobilizá-las para contribuir ativamente para a melhoria contínua, por meio da identificação das causas e da criação dos mecanismos necessários para que as falhas e erros não tornem a ocorrer.

Segundo Imai (1994), o kaizen tem papel fundamental no sucesso competitivo das organizações. Significa pequenas mudanças realizadas no status quo, como resultado dos esforços contínuos. O kaizen também contribui para a construção do aprendizado por meio do envolvimento direto dos colaboradores das áreas estudadas no gemba (local de trabalho).

\section{O processo de mudança e o aprendizado organizacional}

Segundo Bruno (2007), todas as vezes que se quer modificar a situação atual, passando por uma transição até chegar a situação desejada, o que se quer, de fato, é uma mudança organizacional. Portanto, para promover uma mudança efetiva e sólida, deve-se estabelecer um processo de transformação devidamente gerenciado em todas as suas etapas. Pode-se ainda dizer que existe uma 
mudança, quando por algum fenômeno, a realidade é diferente aos padrões ou as expectativas préestabelecidas (figura 1).

FIGURA 1 - O processo de mudança

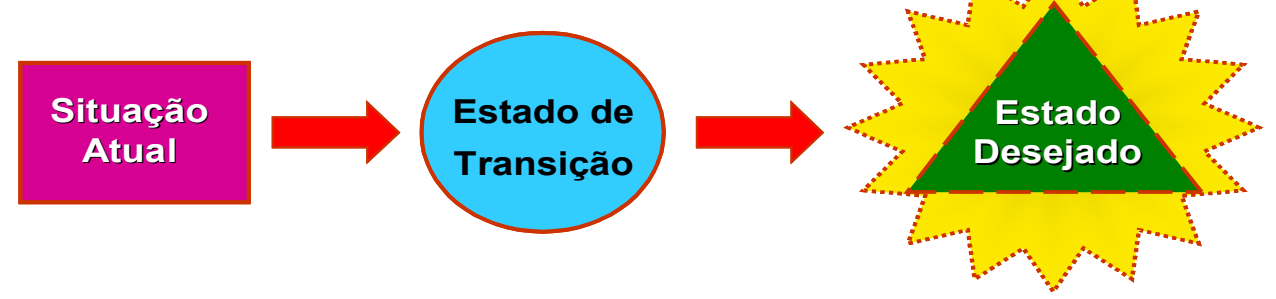

Fonte: Adaptado de Bruno (2007).

Para o autor, os momentos de transformações constituem potencialmente uma oportunidade para a reorganização dos processos de um modo que haja eficácia e evolução. Com a evolução, as necessidades e os desejos mudam e conseqüentemente os valores e costumes das pessoas, surgindo assim à possibilidade de que as organizações também mudem e se adaptem ao novo contexto social.

Entretanto, sendo um processo, deve ser construído e sedimentado etapa por etapa passando por uma transição que promova a mudança do estado atual para o estado desejado, caso contrário, não há como quebrar os costumes e tradições existentes.

Portanto, gerenciar esse processo requer um suporte às transições organizacionais ou pessoais de uma situação atual para resultados futuros desejados por meio da implementação de estratégias e atividades que minimizem o impacto humano, reduzam as perdas financeiras e reduzam o tempo de implementação.

Para Senge (2004) é necessário que as organizações se tornem aprendizes, capazes de reagir às mudanças, solucionar problemas e aproveitar oportunidades. Portanto, para promover transformações organizacionais, necessita-se primeiramente de uma mudança na mentalidade do indivíduo.

Neste sentido, o autor é categórico ao afirmar que nas organizações de aprendizagem, as pessoas aprimoram continuamente suas capacidades de criar e recriar o estado futuro em ações conjuntas, objetivando a conscientização da equipe, através de mudanças e de alterações pessoais para que possam questionar constantemente seus modelos mentais e criarem ambientes seguros para que outras pessoas possam fazer o mesmo. 


\section{O modelo para o gerenciamento da mudança}

O estudo de caso foi desenvolvido e aplicado na empresa aqui chamada de Alfa. Essa empresa é uma indústria transacional do setor eletro-eletrônico, localizada no PIM (Pólo Industrial de Manaus). Basicamente, a fábrica está composta por cinco departamentos produtivos: Estamparia, Injeção Plástica, Pintura e Montagem, além dos outros setores de suporte, tais como: Manutenção, Engenharia, Recursos Humanos, Compras, entre outros. Possui aproxidamente 700 funcionários entre diretos e indiretos.

As ferramentas da MPT e 5s foram aplicadas nos setores de Estamparia e Oficina de Manutenção. Essas áreas foram definidas na reunião de abertura do projeto entre pesquisador e alta administração, pois, segundo informações da mesma, a área de estamparia é considerada o "gargalo da fábrica". O mesmos afirmam que as máquinas apresentam altos índices de peças defeituosas e quebras constantes do equipamento, os quais comprometem os resultados do processo produtivo.

O setor possui 04 prensas de estampagem que funcionam em série, o qual responde pela fabricação de 8 componentes diferentes, portanto, considera-se como uma unidade de produção. A máquina em questão foi também confirmada pelos colaboradores participantes da pesquisa-ação (operadores e técnicos), pois, trata-se do equipamento que mais apresenta problemas para a empresa.

A oficina de manutenção também foi à área escolhida para aplicar o modelo, pois apresenta alto grau de abandono em relação aos $5 \mathrm{~s}$, portanto, requerendo uma mudança efetiva na organização e ambiente de trabalho. A idéia é fazer com que ambos, operadores e técnicos, possam trabalhar em equipe para mudar as duas áreas, além de promover um ambiente de sinergia entre cliente interno (operadores) e fornecedor interno (manutenção).

As etapas que compreendem o modelo são as seguintes: patrocínio, sensibilização, diagnóstico, kaizen, padronização, resultados, reconhecimento e replicação horizontal. O modelo gira no sentido horário e deve ter seu início pela etapa do patrocínio, sem o qual é impossível estabelecer um processo de mudança. Vale lembrar que seguir a seqüência estabelecida pelo modelo, sem suprimir etapas, é fundamental para o sucesso do mesmo.

No centro do modelo está a comunicação, atuando de forma decisiva para o bom funcionamento do ciclo, sem o qual não é possível alavancar os resultados. A comunicação garante que as 8 etapas funcionem de forma integrada (figura 2). 
FIGURA 2 - O modelo de gestão e suas etapas

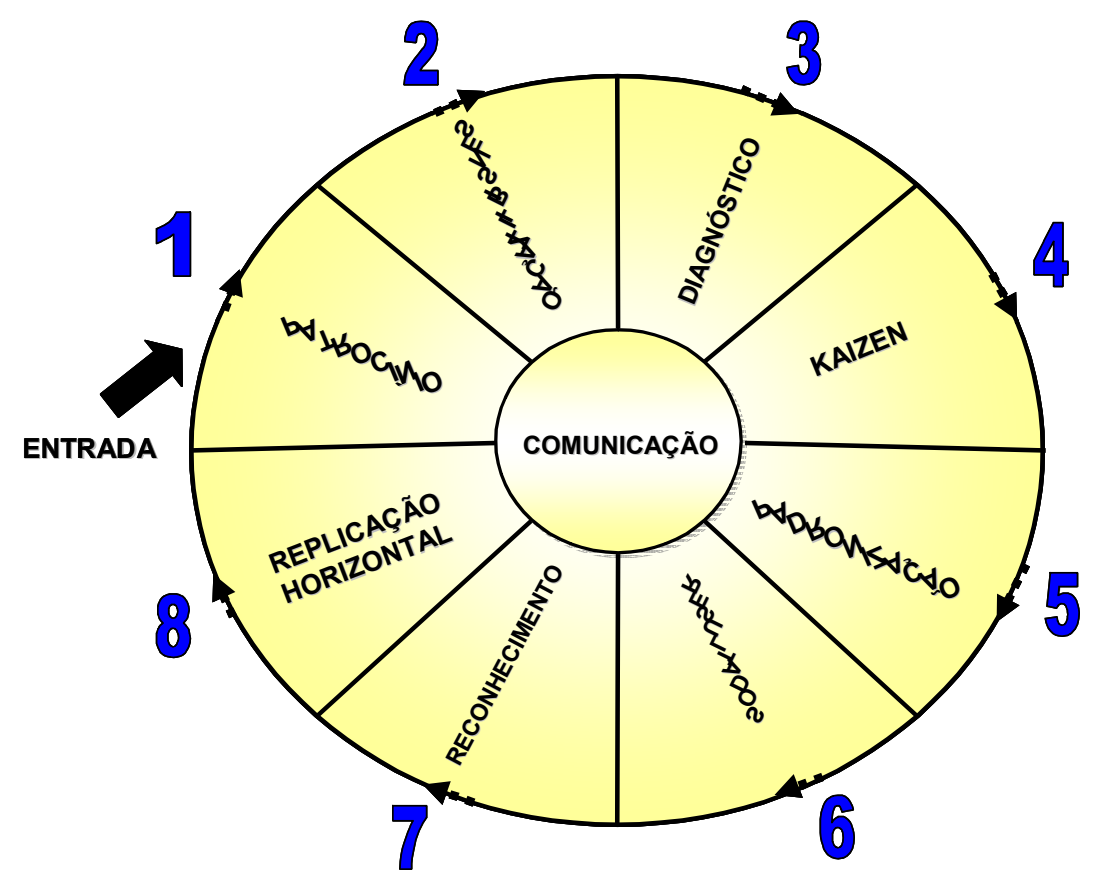

Fonte: $\mathrm{O}$ autor

Durante a primeira etapa, o pesquisador realizou a apresentação inicial do modelo para a empresa por meio de uma reunião com a alta administração (diretor e gerentes), a fim de explanar os objetivos, os métodos, as etapas a serem realizadas e os resultados esperados. Foi neste momento que se definiram as áreas que primeiramente seria aplicado o modelo, bem como foram definidos os participantes do estudo, tais como: o patrocinador e os colaboradores que fazem parte ativa na execução das atividades.

Bruno (2007) destaca a necessidade primária de se definir os papéis para o processo de mudança, são eles: O patrocinador no nível hierárquico adequado (o gerente da área piloto), provendo recursos e suporte; Os agentes de mudanças (os colaboradores participantes do estudo) que foram capacitados para atuar ativamente no processo de mudanças; O "advogado" da mudança (o pesquisador) que irá conduzir e atuar em conjunto com os agentes da mudança; Os objetos de mudança (os colaboradores participantes, o ambiente organizacional e indicadores de desempenho da área escolhida).

Durante a segunda etapa, o pesquisador realizou a sensibilização de todos os participantes da área escolhida por meio de um treinamento in company (treinamento realizado dentro das dependências da empresa) com carga horária de 40 horas, pelo qual abordou os principais conceitos, ferramentas e técnicas utilizadas no estudo.

Antes do início do treinamento, realizou-se também uma pequena cerimônia de abertura do projeto que contou com a participação da alta administração, os quais reafirmaram o compromisso com a mudança. Na ocasião, os gestores tiveram a oportunidade de expor os seguintes tópicos: 
destaque para a pergunta "por que estamos aqui?"; destaque para a importância da capacitação por meio do treinamento; destaque para os participantes que serão pioneiros no projeto, portanto, tornar-se-ão referência na empresa; destaque para os benefícios adquiridos com o novo aprendizado e destaque para as expectativas da empresa.

Segundo Luft (2002) treinar se define como tornar alguém hábil, destro para o desempenho de alguma atividade, exercitar. Nesse contexto, o treinamento serviu para desenvolver o conhecimento básico e científico dos conceitos, filosofias, ferramentas e técnicas que foram utilizados no desenvolvimento do modelo. Ainda nesta etapa, foram formados os times de kaizen com a distribuição das responsabilidades de cada participante.

Durante a terceira etapa, o pesquisador e participantes realizaram um diagnóstico do estado atual nas áreas, o qual serviu como base pré-liminar para as ações de mudança. O diagnóstico é o resultado da visita ao local de trabalho dos participantes e tem como objetivo descrever os entraves constatados nas áreas estudadas por meio do convívio diário com os colaboradores dos setores de manutenção e produção da empresa. Portanto, reflete o resultado das observações do pesquisador somado as percepções dos colaboradores.

Primeiramente, o pesquisador iniciou uma aproximação com os participantes da pesquisa, a fim de "auscultar" os problemas existentes na área por meio de uma conversa informal. Foi nesse momento que o pesquisador procurou observar, conhecer, inquirir e analisar os dados e fatos que ajudaram a identificar os aspectos formais (visíveis) e os informais (invisíveis) dos processos de trabalho, os fluxos de comunicação e as inter-relações entre as áreas cliente (produção) e fornecedor (manutenção) interno.

Os participantes também se deslocaram para as áreas, os quais tiveram a oportunidade de fazer in loco uma auto-avaliação da situação atual. Os mesmos registraram todas as irregularidades constatadas durante a verificação, considerando todo o aprendizado teórico adquirido durante o treinamento de sensibilização. As equipes também procuraram verificar oportunidades de melhorias para aumentar a segurança no trabalho, melhorar a qualidade do processo, otimizar a execução da operação, reduzir os custos relacionados ao trabalho e melhorar a condições ambientais da área, entre outros.

Segundo Liker (2005) o diagnóstico pode começar simplesmente com um comentário do tipo "as coisas não estão fluindo tão bem como costumava acontecer" ou "por que os resultados de tal ação estão abaixo do esperado?”. Juntar informações pode incluir análise de documentos existentes, observação das rotinas cumpridas pelos recursos humanos ou entrevistas e conversas com as pessoas que se relacionam com a organização.

Durante a quarta etapa, as atividades previamente planejadas foram efetivamente realizadas, aplicando na prática os conceitos e ferramentas da mudança. A finalidade, portanto, foi efetuar as 
contramedidas para os problemas detectados durante a etapa anterior e ainda outros que porventura poderiam aparecer durante os trabalhos de "aprender fazendo".

O kaizen foi um momento de intensa atividade prática no gemba da produção e da manutenção, pois todos os participantes tiveram a oportunidade de aplicar os conhecimentos adquiridos no treinamento da etapa de sensibilização. O efeito desse processo foi o efetivo comprometimento de toda a equipe em todas as ações planejadas, pois, verificou-se que todos os participantes estavam unidos por um objetivo comum.

Ré et al. (2007) afirmam que as empresas devem articular uma relação de confiança e compreensão entre os membros da organização, a fim estimulá-los a trocar informações e criar ambientes organizacionais que facilitem a socialização do conhecimento, pré-requisitos para a criação de um ambiente de aprendizagem.

O momento também capacitou os participantes a mudar o estado atual que eles próprios haviam diagnosticado, portanto, tiveram a oportunidade de experimentar um ambiente de aprendizado, além do desenvolvimento da criatividade por meio da captação das idéias inovadoras, além da captação do conhecimento tácito dos operadores e técnicos. Nesta etapa, fez-se a integração das ferramentas da MPT e os 5s, deixando claro que a implementação de uma depende da outra, o qual deve começar com a limpeza básica, inclusive do piso da área de trabalho e, posteriormente, das áreas, máquinas e locais de difícil acesso que contribuem para o acumulo de sujeiras, causando quebras e defeitos.

Segundo Liker (2005), o desenvolvimento humano é a essência para o sucesso da aplicação de qualquer ferramenta ou método. Capacitar e dar autonomia aos técnicos e operadores a enxergar e eliminar os problemas foi fundamental para obtenção dos resultados esperados. Essa autonomia criou uma conexão entre eles, fortalecendo o relacionamento fornecedor-cliente interno entre as áreas, no qual todos acabam sabendo exatamente qual é seu papel no processo de renovação organizacional.

Durante a quinta etapa, a equipe aplicou as técnicas do controle visual e o do trabalho padronizado, a fim de estabelecer um processo padrão para que os itens melhorados se tornem rapidamente visíveis no local de trabalho permitindo que todos visualizem imediatamente a situação padrão, bem como o reconhecimento da situação não-conforme. O objetivo é que ações sejam tomadas para que se retorne rapidamente à condição normal (padrão).

Foi o momento em que os próprios participantes elaboraram os novos procedimentos e rotinas de trabalho, incluindo todas as atividades, melhorias e idéias que eles próprios sugeriram na etapa de kaizen. O objetivo foi disseminar o conhecimento e sistematizar as mudanças por meio da formalização do estado alcançado. Desta forma, transformou-se todo o conhecimento tácito (informal) em conhecimento explícito (formal), pelos quais todos na organização têm acesso. A 
padronização consolidou as melhorias alcançadas e preparou as pessoas e o ambiente de trabalho para um novo nível de mudança, sem o qual não seria possível garantir a sustentação do nível alcançado.

Segundo Liker (2005) os padrões e instruções devem ser específicos o suficiente para serem guias úteis, e ainda generalistas o suficiente para permitir a flexibilidade e o fácil entendimento para qualquer pessoa que irá usá-lo. É importante utilizar as idéias dos próprios funcionários para aprimorar as instruções de trabalho, dando a oportunidade para que eles possam contribuir para a melhoria contínua no processo.

Durante a sexta etapa, as equipes realizaram a confirmação dos resultados obtidos por meio da confrontação das oportunidades de melhorias registradas no diagnóstico do gemba, apresentando os registros do antes e depois (gráfico de inspeção $5 \mathrm{~s}$ ), bem como a melhoria no indicador da Eficiência Global do Equipamento (gráfico de EGE).

Após o fechamento das atividades planejadas e a consolidação dos registros do antes e depois, as equipes preparam o relatório final para ser apresentado a alta administração, com a apresentação de todas as melhorias alcançadas durante o processo de mudança. Nessa etapa, destacou-se a evolução do estado atual para o estado desejado, demonstrando as atividades realizadas durante o processo de transição, inclusive as padronizações realizadas que garantiram a manutenção do novo estado alcançado.

Durante a sétima etapa, realizou-se o reconhecimento público dos esforços alcançados pelos participantes, os quais passaram a se tornar uma referência interna para outras áreas que ainda não haviam passado pelo mesmo processo de aprendizado. Os mesmos tiveram a oportunidade de apresentar os resultados obtidos para a alta administração. Desta forma, procura-se estabelecer uma comunicação mais aberta entre os participantes da equipe e a alta administração.

A satisfação e o reconhecimento pelo desempenho alcançado foram os principais fatores que estimularam os times, pois despertou um sentimento de contentamento pela própria atuação durante o projeto. O reconhecimento dos lideres pelo desempenho alcançado proporcionou a felicidade e o bem estar dos colaboradores.

$\mathrm{Na}$ ocasião, a alta administração ratificou o total apoio para o projeto, bem como demonstrou que pretende exercer uma gestão com característica predominantemente participativa e fundamentada em um clima de confiança entre lideres e liderados. A alta administração efetivamente reconheceu os esforços do nível operacional como uma parte relevante do processo de transformação.

O reconhecimento também foi registrado pela entrega do certificado de conclusão do treinamento que foi realizado no estágio de sensibilização, a fim de formalizar o aprendizado individual de todos os colaboradores. Vale lembrar que um reconhecimento adequado motiva os 
colaboradores para uma participação espontânea em outros projetos de melhorias na organização, bem como a manutenção do nível atual alcançado.

Dutra (2002) propõe uma integração entre as pessoas e a organização colocando-as lado a lado e viabilizando um processo contínuo de desenvolvimento mútuo. As organizações criam condições para aprimorar a capacitação das pessoas, contribuindo diretamente para a sua empregabilidade. As pessoas, por sua vez, ao melhor se qualificar, transferem para a organização o seu aprendizado enriquecendo o patrimônio de conhecimento organizacional e, conseqüentemente, fortalecendo suas vantagens competitivas.

A oitava etapa, marca o fim do primeiro ciclo do modelo de gestão da mudança e aprendizado organizacional. Portanto, abre-se a oportunidade de continuar efetuando novos ciclos para as mesmas áreas do estudo, assim como também a disseminação para outras áreas da organização. É nesta etapa que ocorreu a reunião de fechamento do pesquisador com a alta administração, no qual foram apresentados todas as etapas do desenvolvimento do estudo, resultados alcançados e a sugestão para que o projeto fosse desdobrado para outras pessoas e áreas da empresa.

Segundo Imai (1996) deve-se padronizar as mudanças alcançadas por meio da consolidação do novo nível atingido após um giro do ciclo de melhoria. A padronização ocorre pela estabilização e sistematização do processo atual, pelo qual são estabelecidos padrões para os produtos e o processos. Somente após a estabilidade é que se pode começar a trabalhar em novos ciclos de mudanças.

A comunicação é atividade central do modelo, pois foi um fator que sempre esteve presente durante os trablhos. O objetivo foi manter os participantes e a alta administração sempre informados sobre as atividades de cada etapa. A realidade foi que o sucesso do estudo esteve diretamente ligado com a qualidade das informações produzidas.

A comunicação foi fundamental para fazer a ligação entre uma fase e outra, proporcionando uma interação efetiva entre pesquisador, colaboradores e alta administração. A comunicação também manteve a equipe alinhada em relação as atividades a serem realizadas em cada fase do modelo. Durante o processo de comunicação, pôde-se tornar público as mudanças promovidas nas áreas, dando a oportunidade para que outras áreas também pudessem desenvolver uma percepção positiva em relação à mudança alcançada.

\section{Resultados alcançados}

O resultado da aplicação do modelo de gestão, composto pelas 8 etapas sucessivas, foi um gerenciamento eficaz do processo de mudança, pelo qual a empresa pôde identificar a situação atual 
que se encontrava, assim como também o planejamento e o controle da transição até o alcance do estado desejado (figura 3).

FIGURA 3 - Aplicação do modelo para o gerenciamento da mudança

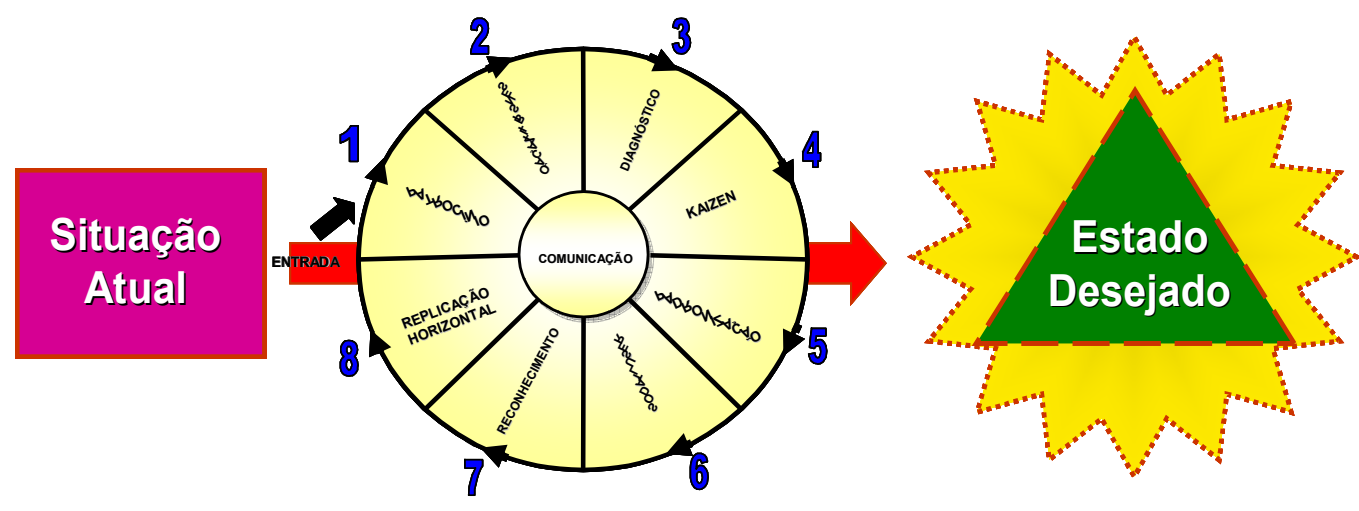

Fonte: $\mathrm{O}$ autor

Com relação a evolução do resultado dos $5 \mathrm{~s}$, utilizou-se o auxílio da já existente equipe de inspeção da empresa Alfa que antes já estava desmotivada com a situação permanente das áreas. No entanto, as atuais evidências das mudanças no ambiente de trabalho e na atitude dos técnicos e operadores, proporcionaram uma nova motivação para que as inspeções de $5 \mathrm{~s}$ fossem reativadas, uma vez que as mesmas já estavam abandonadas devido ao descaso existente com relação ao $5 \mathrm{~s}$ em todas as áreas da empresa.

Para o registro do processo de transformação, realizado no mês de agosto de 2008, foram realizadas 6 inspeções com o intuito de observar a evolução dos resultados da mudança provocada pelos 5s. A primeira delas foi realizada na etapa de diagnóstico, o qual apresentou um percentual de $31,2 \%$ de conformidade, a segunda durante o kaizen, o qual já apresentou uma evolução para 73,1\% de conformidades, as outras duas inspeções foram realizadas após a conclusão de todas as etapas do modelo, seguindo intervalos de 1 semana, portanto, apresentando os resultados de $88,2 \%$ e $91,4 \%$, respectivamente (gráfico 1).

Para a confirmação da efetividade do modelo, foram realizadas ainda inspeções nos meses de setembro e outubro, o qual obtiveram os resultados de $92,5 \%$ e 93,5\% de conformidades para os $5 \mathrm{~s}$ aplicados e mantidos após a realização do estudo. 
GRÁFICO 1 - Resultado das inspeções dos $5 \mathrm{~s}$

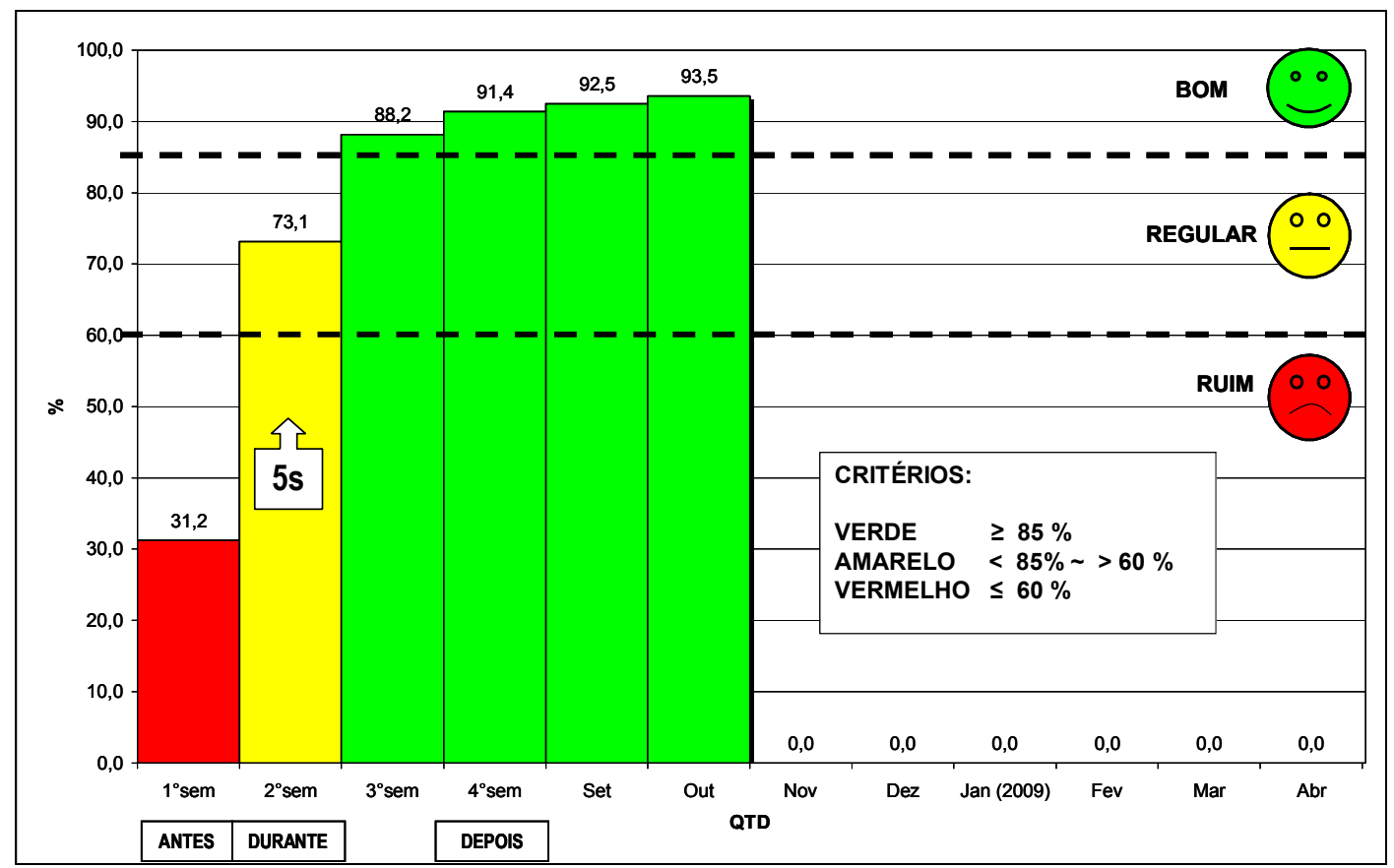

Fonte: Adaptado da empresa Alfa

Para a evolução do resultado da MPT, na unidade de produção das prensas, foi registrado o indicador da eficiência global do equipamento por meio do sistema de informação já existente na empresa Alfa. O histórico dos resultados anteriores apresentavam dados ruins, os quais apresentaram um desempenho de 60,76\% para a média de 2007. Também foi constatado a continuidade de baixo desempenho no primeiro semestre de 2008, com um desempenho de 59,77\%. Portanto, números que justificam a insatisfação atual da alta administração.

Durante o processo de desenvolvimento e aplicação do modelo, realizado no mês de agosto de 2008. Porém, já no mês de implantação do modelo, foi registrado uma evolução na melhoria da eficiência global do equipamento para $69,46 \%$. Para a confirmação da efetividade do modelo, foram coletados ainda outros dados nos meses de setembro e outubro, os quais obtiveram os resultados de $80,34 \%$ e $84,36 \%$ de desempenho, acima da meta estabelecida e confirmando a efetividade do modelo (Gráfico 2). 


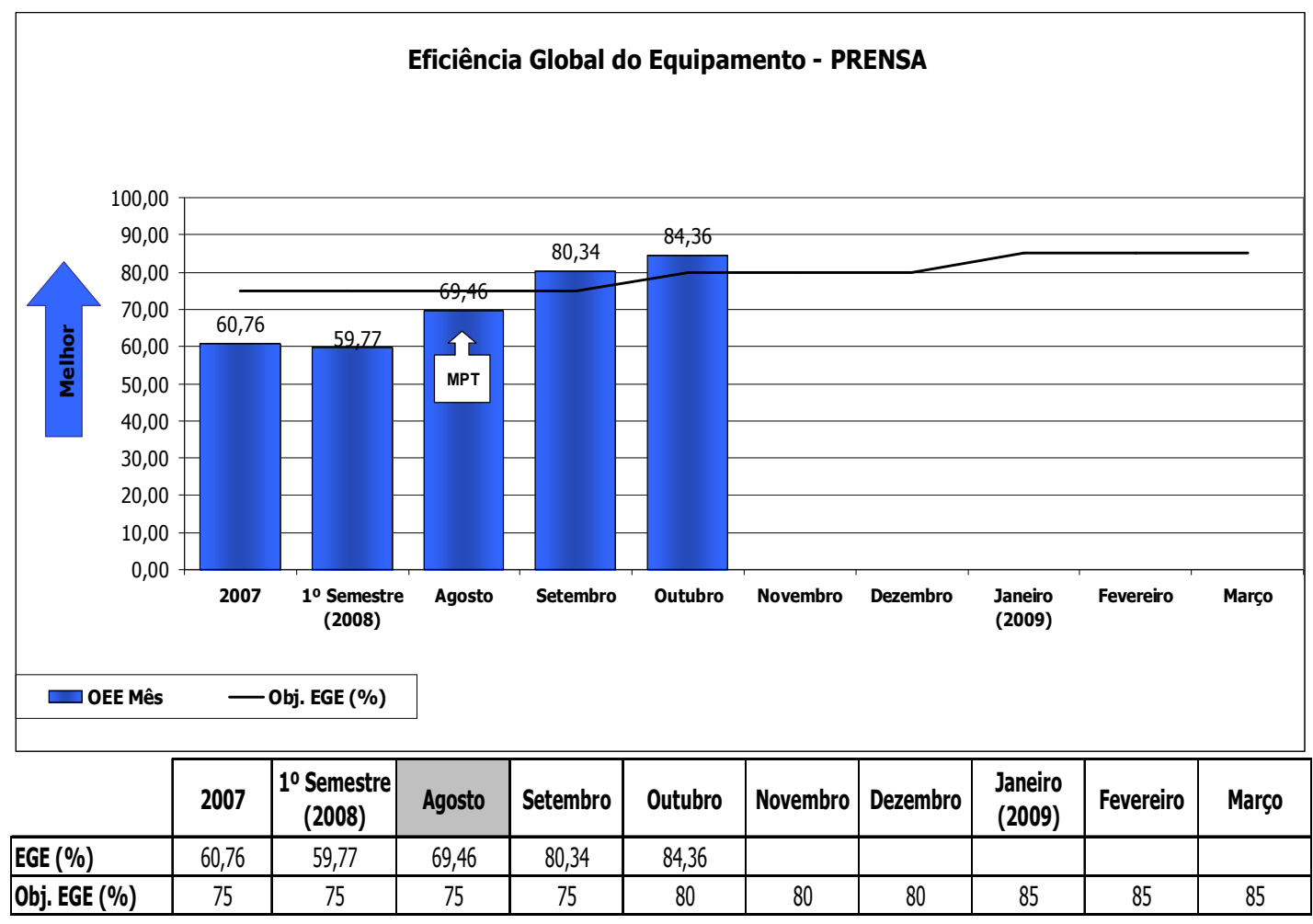

Fonte: Adaptado da empresa Alfa

\section{Considerações finais}

Atualmente, a palavra "mudança" se tornou um termo imperativo nas empresas globais, contudo, muitas delas não conseguem alavancar as transformações necessárias em cada componente da organização como forma de garantir a própria sobrevivência. Ocorre que a renovação organizacional sofre mudanças ao longo do tempo, mesmo que as organizações resistam a elas, portanto, devido ao atual cenário de competitividade entre as empresas, esperar que as transformações aconteçam por simples inércia é estabelecer uma rota certa rumo ao fracasso.

É neste contexto que o modelo desenvolvido está inserido como uma metodologia capaz de gerir com efetividade a transição do estado atual para o estado desejado. O estudo também se torna bastante relevante para o setor industrial, uma vez que foi totalmente aplicado na prática do dia-adia de uma empresa transacional.

Com relação aos resultados alcançados, comprovou-se uma efetiva gestão da mudança e o estímulo ao aprendizado organizacional, o qual promoveu melhorias nos processos, no ambiente de trabalho, na melhoria dos indicadores de desempenho e na participação ativa dos colaboradores em equipes de ação.

O modelo também estimulou o desenvolvimento da autonomia necessária para que os colaboradores possam melhorar seus próprios processos, estimulando a iniciativa e a criatividade. 
Essa autonomia acabou criando uma conexão entre as eles, fortalecendo o relacionamento interpessoal entre fornecedor (técnico) e cliente (operador). Esse novo relacionamento permitiu que as áreas pudessem compartilhar novas idéias, trazendo benefícios para ambas as partes, melhorando e facilitando as atividades do dia-a-dia.

Os ciclos de gestão também marcaram o início de uma empresa com características culturais próprias, por meio de um ambiente uniforme e de aprendizado contínuo. Essa transformação cultural desenvolveu nas pessoas certo grau de segurança, fazendo com que percebam que fazem parte de um time e as liberando para criar idéias que agregam valor.

Conclui-se, portanto, que o modelo contribui de forma relevante a uma necessidade de mudanças contínuas, cada vez mais emergentes nas organizações. Vale lembrar que a concorrência sempre estabelece uma forma de copiar as vantagens competitivas antes desenvolvidas, portanto, possuir boas operações não garante o sucesso do amanhã. É necessário desenvolver uma vantagem competitiva sustentável e que seja um diferencial único da empresa, isto é, algo como a personalidade humana, o qual cada indivíduo se torna único em suas características e jeito de ser.

O artigo não pretende esgotar a aplicabilidade do modelo, uma vez que o mesmo abre a oportunidade para que outros trabalhos possam ser realizados a partir deste. Portanto, espera-se que outras pesquisas em diferentes setores organizacionais, tais como o público e o de serviços, possam utilizar o modelo aqui desenvolvido em seus processos, a fim de promover as mudanças desejadas.

\begin{abstract}
The high competitive market that companies are envolved with is the main factor to enteprises adopt an continium change atitude, otherwise, they are in risk to discard by the market who are more and more severe in chose their partner. However, change management is not a simple task, because need an apropriate management of transition process that should be build and consolidate step by step, involving behavior change, thinking, feeling and perception that were inside of people mind who is part of company identity. In that context, the article show a management model that use technical and tools to develop the management from actual condition to the desired condition and with the development of a mind to continius learning. The conclusion of this study revel that he model contribute to superate the old paradigm, promoting the necessary adjustment to high performance cultural organization, estimulating the team spirit, the improvement of operation performance and the job environment.
\end{abstract}

Key-words: change management, learning organization, 5s, MPT, kaizen.

\title{
10. Referências
}

ANDAlOUSSI, K. El. Pesquisas-Ações: Ciência, Desenvolvimento, Democracia, São Carlos: Edufscar, 2004.

BAIN \& COMPANY, 2003. Disponível em: <http://www.bain.com/bainweb/PDFs/cms/ Public/insead_making_change_stick.pdf>.Acesso em: 25 jul. 2008.

BRUNO, C. F. L. Gestão da Mudança Organizacional. Manaus: [S.n], 2007. (Apostila da disciplina Gestão do Comportamento Organizacional, Curso de Mestrado Profissional em Engenharia de Produção, Universidade Federal do 
Amazonas).

DUTRA, J. S. Gestão de pessoas: modelo, processos, tendências e perspectivas, São Paulo: Atlas, 2002.

IMAI, M. Kaizen: a estratégia para o sucesso competitivo. 5. ed. São Paulo: IMAM, 1994.

IMAI, M. Gemba-Kaizen: estratégias e técnicas do Kaizen no piso de fábrica. São Paulo: IMAM, 1996.

LIKER, J. K. O Modelo Toyota: 14 Princípios de Gestão do Maior Fabricante do Mundo. Porto Alegre: Bookman, 2005.

LUFT, C.P. Minidicionário Luft. Ática. 20ª Edição. São Paulo, 2002.

OHNO, T. O Sistema Toyota de Produção - além da produção em larga escala. Porto alegre: Bookman, 1997.

PALADINI, E. P. Gestão da qualidade: teoria e prática. São Paulo: Atlas, 2000.

PALMEIRA, J. N.; TENÓRIO, F. G. Flexibilização Organizacional. Rio de Janeiro: Fundação Getúlio Vargas, 2002, 279p.

PORTER, M. E. Competição: Estratégias Competitivas Essenciais. Harvard School Business Press, 1999.

RÉ, T. A. C.; LIMBERGER, J. S.; VIANNA, B. W.; CUNHA, A. C. J. C. O Impacto da Cultura Organizacional no Processo de Gestão do Conhecimento. In: XXVII Encontro Nacional de Engenharia de Produção, Foz do Iguaçu, PR, Brasil, p. 1- 10. CD-ROM, 2007.

SENGE, P. M. A Quinta Disciplina: arte e prática da organização que aprende. 16 ed. São Paulo: Editora Nova Cultural, 2004.

SHARMA, R. K.; KUMAR, D.; KUMAR, P. Manufacturing excellence through TPM implementation: a practical analysis. Industrial Management \& Data Systems. Vol. 106, n. 2, p. 256-280, 2006.

cross'ref

SILVA, C. E. S. Um programa passageiro ou permanente. 2001

TAVARES, A. L. Planejamento, Controle e Gestão de Manutenção. Manaus: [S.n], 2007. (Apostila da disciplina Gestão da Manutenção, Curso de Mestrado Profissional em Engenharia de Produção, Universidade Federal do Amazonas).

Dados dos autores:

Nome completo: Marcelo Augusto Oliveira da Justa

Filiação institucional: Universidade Federal do Amazonas - UFAM

Departamento: FT - Faculdade de Tecnologia

Função ou cargo ocupado: Mestrando em Engenharia de Produção

Endereço completo para correspondência (bairro, cidade, estado, país e CEP): Rua 30 casa 19, QA37, Conj. Jardim de Versailles, Bairro Planalto, Manaus - Amazonas - Brasil, CEP 69044-770

Telefones para contato: (92) 3656-0012 ou (92) 8179-2273

e-mail: marcelo.justa@bol.com.br 
Nome completo: Prof ${ }^{0}$. Dr. Nilson Rodrigues Barreiros

Filiação institucional: Universidade Federal do Amazonas - UFAM

Departamento: FT - Faculdade de Tecnologia

Função ou cargo ocupado: Coordenador do Curso de Engenharia de Produção

Endereço completo para correspondência (bairro, cidade, estado, país e CEP): Av. General Rodrigo

Otávio Jordão Ramos, 3000, Bairro Aleixo, Manaus - Amazonas - Brasil, CEP 69077-000

Telefones para contato: (92) 3647-4418 / 3647-4432

e-mail: nilbarr@ufam.edu.br 